\title{
A new approximation of mean-time trends for the second wave of COVID-19 pandemic evolving in key six countries
}

\author{
Sergey V. Ershkov (i) Alla Rachinskaya
}

Received: 23 December 2020/ Accepted: 19 January 2021 / Published online: 14 February 2021

(C) The Author(s), under exclusive licence to Springer Nature B.V. part of Springer Nature 2021

\begin{abstract}
We have presented in the current analytic research the generating formulae and results of direct mathematical modelling of non-classical trends for COVID-19's evolution in world which, nevertheless, can be divided into two types: (1) the general trends for European countries such as Germany presented by the curve of modified sigmoid-type with up-inclination of the upper limit of saturation (at the end of first wave of pandemic) as well as for other cases of key countries that suffered from pandemic such as USA, India, Brazil, Russia (we conclude that the same type of coronavirus pandemic is valid for most of the countries in world with similar scenarios of the same type for general trends); (2) non-classical general trends for Middle East countries (such as Iran), with the appropriate bulge on graphical plots at the beginning of first wave of pandemic. We expect that the second wave of pandemic will pass its peak at the end of December 2020 for various countries. Moreover, the second wave of pandemic will have come to end at first decade of January 2021 in Germany and Iran (but at
\end{abstract}

S. V. Ershkov ( $\square)$

Plekhanov Russian University of Economics, Scopus

Number 60030998, 36 Stremyanny Lane, Moscow, Russia 117997

e-mail: sergej-ershkov@yandex.ru

\section{A. Rachinskaya}

Odessa I. I. Mechnikov National University, 2

Dvoryanskaya St, Odessa, Ukraine

e-mail: rachinskaya@onu.edu.ua the end of January 2021 in India as well), so we should restrict ourselves in modelling the first and second waves of pandemic within this time period for these countries. Thus, the model of first approximation is considered here which allows to understand the meantime trends of COVID-19 evolution for the first + second waves of pandemic for USA, Brazil and Russia, or predict the approximated time period of the upcoming third wave of pandemic in cases of India, Germany and Iran.

Keywords COVID-19 - Chains of recurrent sequences $\cdot$ Second wave of pandemic

"Beware that, when fighting monsters, you yourself do not become
a monster... for when you gaze long into the abyss. The abyss gazes
also into you" Friedrich Nietzsche

\section{Introduction, basic approach}

In this paper, we present a new interpretation of a semi-analytical research with respect to analysis of the COVID-19 virus evolution [1] over the world up to date [2]. This article continues modelling study as presented earlier [1].

We have presented previously a heuristic mathematical model of the outcome of outbreak, which differs from most of the existing theories for 
describing the evolution of the viruses in human society (mainly, from those which are based on dynamics by modelling with the help of ordinary differential equations or well-known stochastic methods). Namely, the theory of finite recurrent sets or finite chains of recurrent sequences was applied for describing how population evolves over time.

One of the classical examples of using such an approach in theoretical biology is the modelling sunflower patterns in the plant biology via Fibonacci or Lucas numbers [3] (in 1202, Fibonacci published book for learning the Arabic system of math which included Fibonacci's solution to a puzzle focused on predicting the number of bunnies born in one year to a huge family started simply with by two bunnies), or modelling dynamics of population in biology via Tribonacci [4] sequences for animals, sea organisms, insects, plants or trees.

Following by the aforementioned classical traditions, the approach suggested in [1] determines a nonlinear dependence of self-similar rate of evolution process (or dynamics of infected population) in regard to the proper residual capacity of non-infected part of all the humankind to overcome the pandemic. The last is assumed to be associated with "potential of the niche for absorbing the infection", defining a catastrophic acceleration (or optimistic deceleration) of the dynamics of the infected part of population, as below:

$x_{n+30}=(1-\alpha) \cdot x_{n}+\beta \cdot x_{n+5}+\gamma \cdot x_{n+11}$

where $n \in N, x_{n}$ is the number of alive and (presumably) healthy population at the beginning of the current month ( $\alpha$ is the coefficient of migration to other regions [1]); $x_{n+30}$ is the number of alive population at the end of month ( 30 days); $x_{n+5}$ is the number of alive population on 5 th day $(\beta$ is the coefficient for those who have been detected as having been infected after passing the 5-day period); $x_{n+11}$ is the number of alive population on 11th day ( $\gamma$ is the coefficient for those who have been detected as not infected after passing the 11-day period of quarantine).

Then afterwards, semi-analytical algorithm has been proposed in [1] for solving finite difference Eq. (*) along with additional reasonable criterion in the absence of migration of population from the considered country to other regions. The results are formulae of a type (1) or (2) presented for calculating the modified sigmoid curve with inclination for cases of Russia (1) or Germany (2).
For brevity, we do not mention here many classical models often used in epidemiology models, like SIR method and its variants [5]. As for the obvious but important disadvantage of the classical SIR-like models [6-9], the population of alive creatures or humans could not be adequately described by differential approaches in case of middle size (or small amount) of population, because all beings should be accounted as sum of separated units (i.e., of those who could not be presented as infinitesimal differential quantity). Otherwise, ansatz suggested in [1] is based on investigation of equations of a type (*), left part of which is a linear combination of sequences of recurrent finite sets or finite chains of recurrent sequences. Thus, such approach can naturally be applied for describing how population (living organisms or humans) evolves over time. We have suggested absolutely novel theory which describes such epidemiological processes by recurrent finite sets or finite chains of recurrent sequences via semi-analytical algorithm. As for the purpose (and motivation) of the current research, we can formulate it as follows: the main aim is to find a kind of the semi-analytical solving algorithm (preferably, presented by analytical formulae) which describes evolution of pandemic in chosen key six countries with accuracy less than $10 \%$ for the chosen time period. Namely, each obtained semi-analytical algorithm can clarify the structure, intrinsic code and features for the variety of possible solutions (from mathematical point of view) depending on initial data.

As for other similar works, there are no other available models of this type (excluding those where modelling with the help of ordinary differential equations or well-known stochastic methods was carried out). It means the originality and importance of the suggested approach and obtained results coinciding with the data of really observed and confirmed cases of coronavirus pandemic with sufficiently good level of approximation (less than 10\% for the chosen time period for most of the key six countries, namely USA, India, Brazil, Russia, Iran or Germany).

Moreover, emphasizing the main contribution of the study, we will proceed from practical point of view for investigating here the countries where the pandemic evolves by non-classic scenario, for example as it happens in case of USA, India, Brazil, Russia, Iran or Germany. The classical general trend is the simple sigmoid or logistic curve (which stems from our model 
[1]); it can be seen in slightly locally changed form in case of China (Fig. 1).

Otherwise, discussing non-classic scenario, we can interpolate the maximal level of cases of illness, e.g. for Russia, according to formula (1).

As we can see from Fig. 2, there is no classic horizontal trend of sigmoidal type at the end of the first wave of pandemic; it is presented in a form of modified sigmoid curve with inclination. The same conclusion should be made for most of the countries in the world, including Iran (and similar countries from Middle East) or USA, India, Brazil, Russia or Germany.

Let us explain such a non-classical trend of COVID-19 outbreak in case of various countries: as each country imposed and relaxed non-pharmaceutical interventions at different stages of the pandemic, it is difficult to believe that algorithm (1) in [1] with fixed parameter values has any predictive power except classical trend of COVID-19's evolving in human society presented by sigmoidal type of curve (in ideal case of isolated islands countries, for example).

All in all, it means for the cases of non-classical trends of COVID-19's evolving in various countries that we should take into consideration the additional correcting coefficients in the numerators of formulae for the aforementioned modified sigmoid curves.

We should note that formula (1) has been slightly corrected in the current research, according to the updated data regarding the confirmed cases of illness in Russia for the combined first and the second (current) wave of pandemic, with respect to previous formula which was published earlier in [1] only for the first wave of pandemic:

$x_{n_{\text {(Russia) }}}=\frac{130,000(1.64+1.64 \exp (0.01(n-21)))}{(1+\exp (-0.09(n-43)))}$,

where $n$ is the current day from 1 April 2020, which yields Fig. 2. (Meanwhile, the relative deviation between the calculated vs. real data of the COVID19 dynamics is less than $9 \%$ for the data, presented in [2] for the case of Russia, except first 17 days from the beginning of pandemic.)

The approach, suggested previously in [1] by applying chains of recurrent sequences to algorithm of modelling the COVID-19 pandemic, let us obtain the partial discrete solution (of exponential type as in $[10,11])$ which directly stems from such an analytical algorithm and, furthermore, it lets us obtain the general trend of a type of modified sigmoid curve in case of Russia (as mentioned above).

But we should especially note that it is very important for obtaining the appropriate algorithm of COVID-19's evolution in world to adjust accordingly the curve stemming from the theoretical calculations with respect to the real cases of observed dynamics. (Or, in other words, our basic model [1] needs
Fig. 1 Dynamics of total COVID-19 cases for China

\section{Total Coronavirus Cases in China}

linear logarithmic

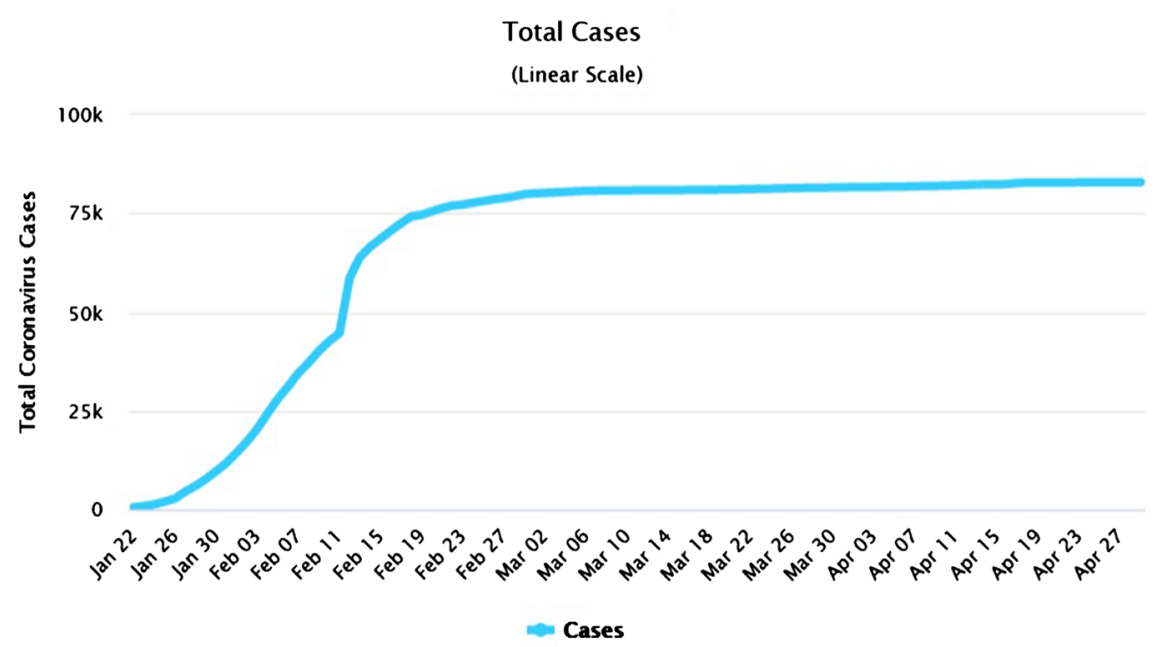


Fig. 2 A schematic cases for Russia. Beginning is 1 April 2020 (here we designate $x=t$, in days, just for presenting the plot) dynamics of COVID-19

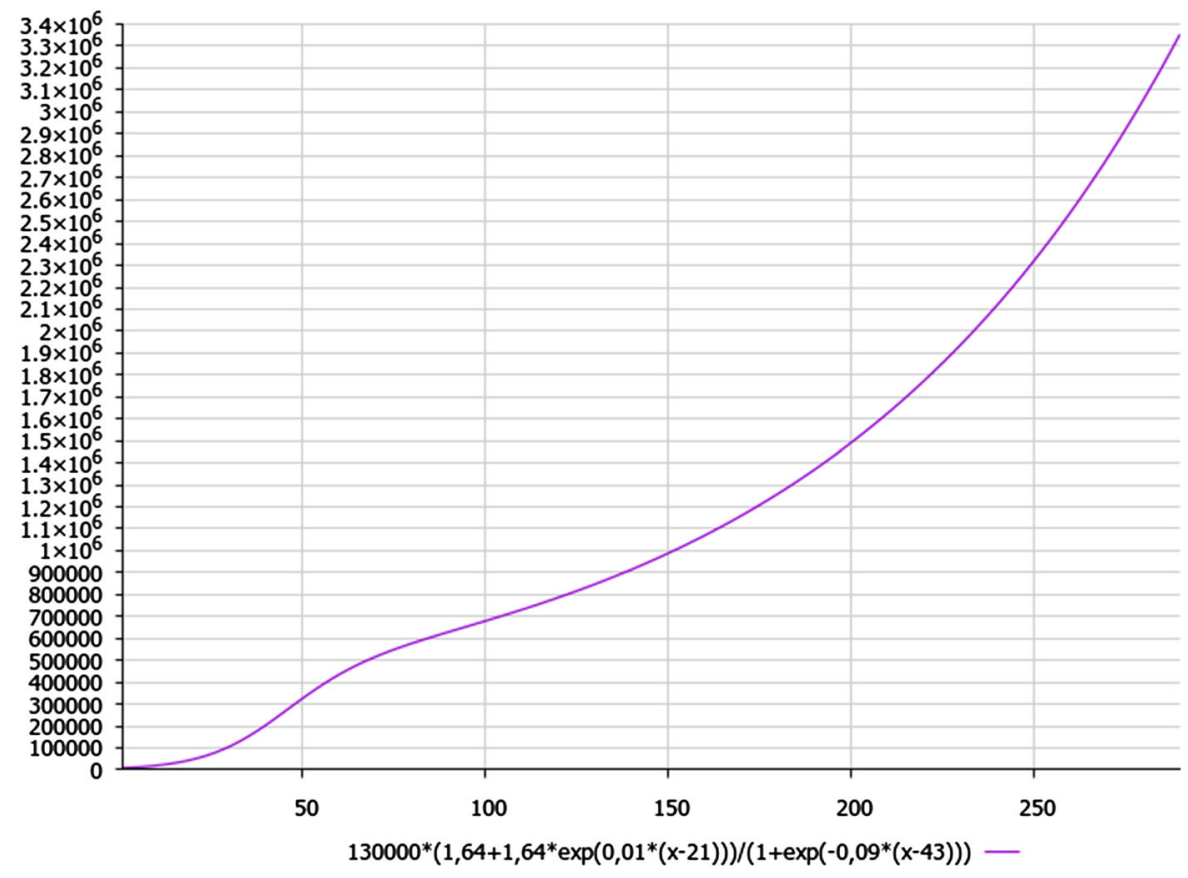

pandemic is the early diagnostic of those who have been infected [12].

data in each country.)

We present in the next sections such examples of the direct mathematical modelling in case of Germany, Iran, USA, Brazil and India. Albeit the basis for such a modelling should be the recurrent sequences, nonetheless we leave constructing the chains of recurrent sequences for theoretical sociology (or mathematical biology) and will concentrate our efforts on the direct mathematical modelling of the pandemic in case of these countries.

We expect that the second wave of pandemic will pass its peak at the end of December 2020 for various countries, so all the approximated formulae for COVID-19's evolution in human society should be corrected afterwards, according to the updated dynamics for the confirmed cases of illness. The main reason is that predicting the future with such a model will obviously have a limited planning horizon due to the unavoidable uncertainty of the future. All coefficients in analytical formulae remain statistically the same if only both the disease characteristics and the societal ones will be in future as they were in the past, which seems unrealistic given the efforts around the globe to diminish the prevalence of COVID-19. One of the obvious ways to diminish the spreading of the current

\section{Direct mathematical modelling of the COVID- 19's cases in Germany}

Let us discuss the non-classical trends of COVID-19's evolution in case of Germany. It is worth to note that coefficients in formula (2a) have also been slightly corrected (according to the updated set of data of coronavirus cases in Germany) with respect to previous formula which was published earlier in [1] for the first wave of pandemic, but such a corrected formula (2a) has been generating correctly the approximated results of calculations during first 8 months up to the end of first wave of pandemic at the end of October 2020

$x_{n_{\text {(Germany) }}}=\frac{90,000(0.87+0.041 \exp (0.036(n-146)))}{0.4+\exp (-0.08(n-25))}$,

where $n$ is the current day from 1 March 2020, which yields Fig. 3a. (We should note that the relative deviation between the calculated by formula (2a) and 
Fig. 3 a A schematic dynamics of coronavirus cases in Germany for the first wave of pandemic. The start is 1 March 2020 (here we designate $\mathrm{x}=\mathrm{t}$, in days). b A schematic dynamics of coronavirus cases in Germany for second wave of pandemic. The start is 1 November 2020 (here we designate $x=t$, in days) a

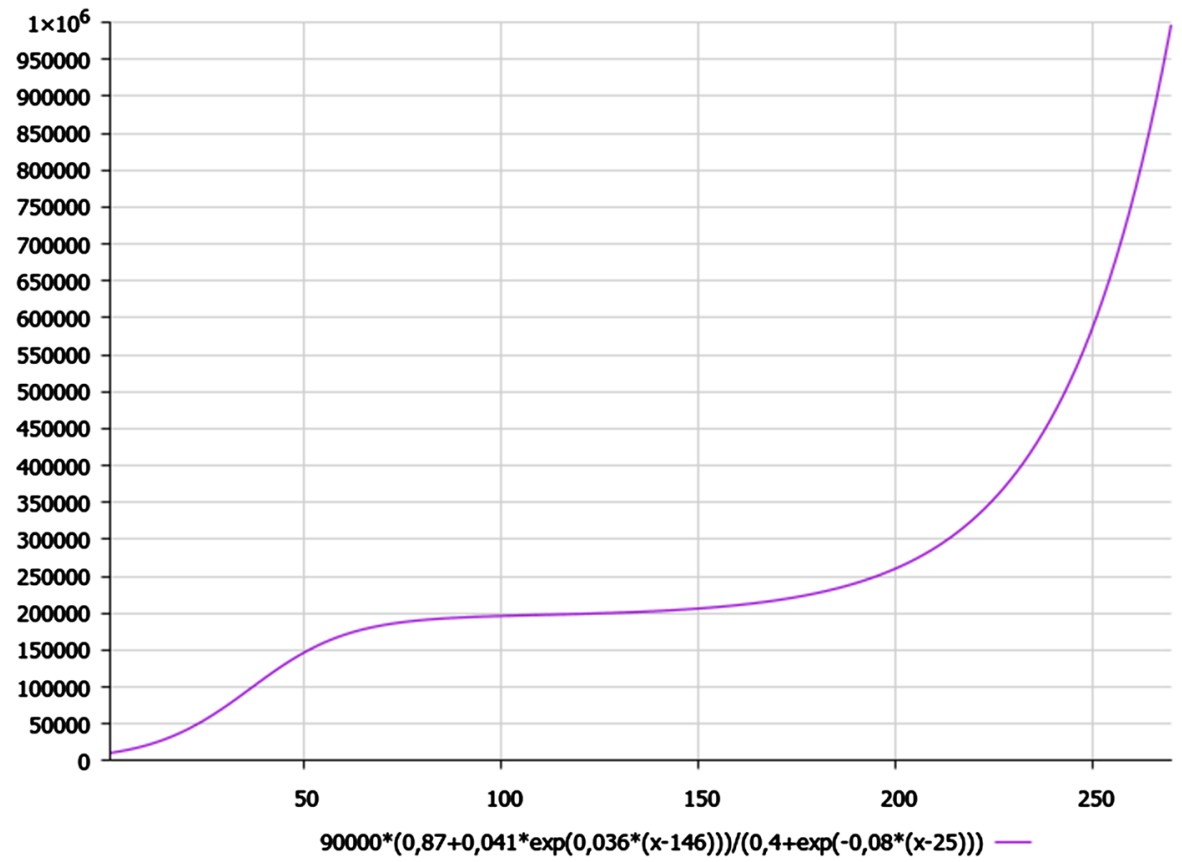

b

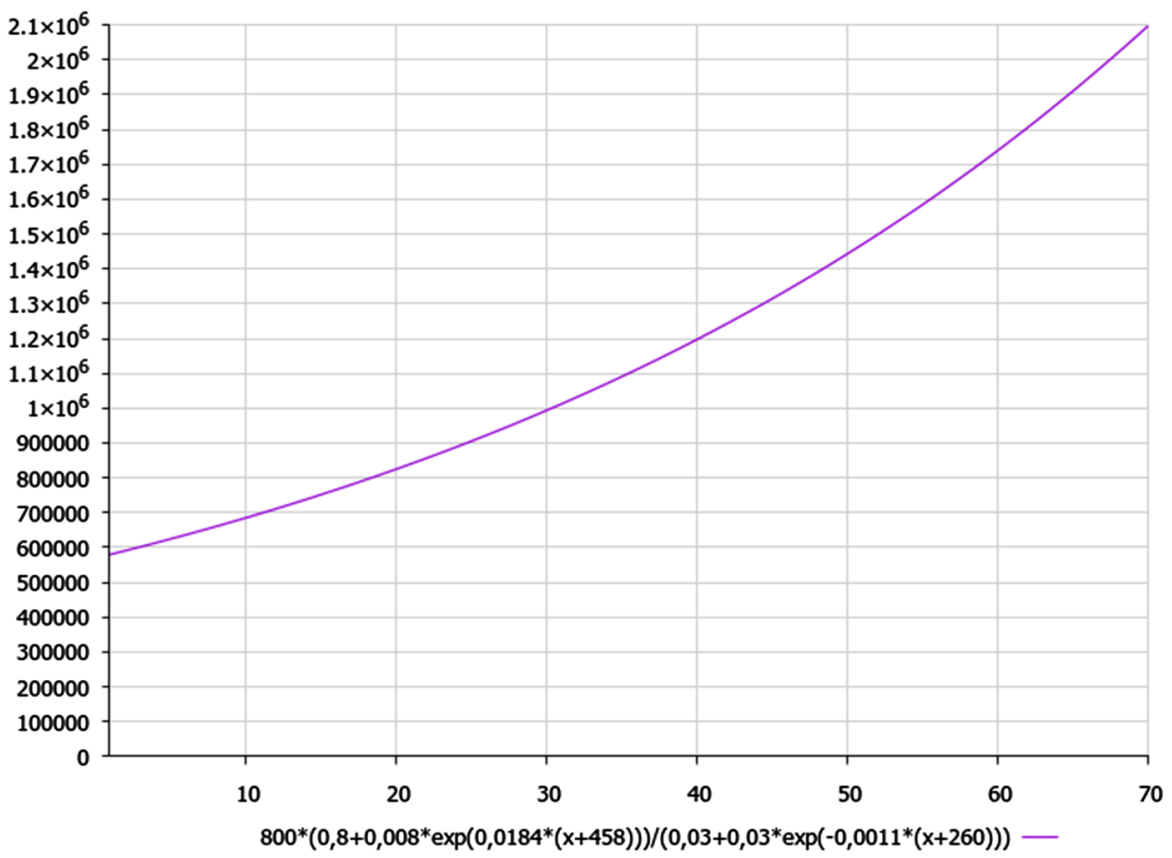

real data of the COVID-19 dynamics is less than $8 \%$ for the data, presented in [2] for the case of Germany, except first 30 days from the beginning of pandemic.)

As we can see from Fig. 3a, the schematic dynamics of coronavirus cases in Germany demonstrates the trend of classical sigmoid curve up to circa 150th day of pandemic (till the beginning of August 2020), whereas the numerator in formula (2a) yields the modified sigmoid curve with up-inclination at the end of first wave of pandemic (at the beginning of November 2020, i.e. up to the circa 250th day of pandemic). 
Then afterwards, the second wave of pandemic has been born (among the relatively stable dynamics of outcome of the first wave) with the generating, bestfitting formula $(2 b)$ :

$x_{n_{(\text {Germany })}}=\frac{800(0.8+0.008 \exp (0.0184(n+458)))}{0.03+0.03 \exp (-0.0011(n+260))}$,

where $n$ is the current day from 1 November 2020, which yields Fig. 3b. (We should note that the relative deviation between the calculated by formula (2b) and real data of the COVID-19 dynamics is less than $9 \%$ for the data, presented in [2] for the case of Germany.)

As we can see from Fig. 3b, the schematic dynamics of coronavirus cases in Germany for the second wave of pandemic demonstrates the trend of classical sigmoid curve close up to its end at the beginning of January 2021, whereas the contribution of numerator in formula (2b) into the final result appears to be negligible till the end of second wave of pandemic in Germany. It is worth to note that we expect that the second wave of pandemic will come to the end at the first decade of January 2021 in Germany, so we should suggest revolving scheme for calculating algorithm with respect to the cascade of waves of pandemic: at each calculation step, the final solution value of the previous stage of pandemic (e.g. at the end of second wave) should be considered to be the initial condition for the next calculation step (at the beginning of the third wave of pandemic).

As for the considerable deviation (in amount circa 35,000 of people) between final solution value of the first wave of pandemic (ending 31st of October) and initial condition for the next calculation step, 1st day of second wave of pandemic started by agreement from 1 November 2020; this fact can be explained by hidden statistics of non-registered cases of illness without obvious symptoms of the disease (COVID19).

\section{Direct mathematical modelling of the COVID- 19's cases in Iran}

Let us present the non-classical trend of COVID-19's evolution in Iran, where we should take into consideration the additional (of other type) correcting coefficients for formulae of a type (1) or (2).
The aforementioned non-classical trend could be presented by the best-fitting formula (3) for mathematical modelling of COVID-19 dynamics in Iran:

$x_{n_{\text {(Iran) }}}=\frac{90,000\left(1.9+\left\{\frac{0.4 \exp (0.014(n-86))}{n^{0.013}}\right\}\right)}{0.72+0.72 \exp (-0.027(n-83))}$,

where $n$ is the current day, starting from 25 February 2020, which yields Fig. 4.

As we can see from Fig. 4, the end of first wave of pandemic seems to be at the second half of May 2020 in Iran (as in Russia), but there is no horizontal trend at the end of first wave of pandemic.

Moreover, there is a bulge on a plot of the first wave of pandemic, determined by additional coefficient $\sim\left(1 / n^{\wedge}(0.013)\right)$ in the numerator of formula (3).

As we can see from Table 1, the deviation of the calculated vs. real data of the COVID-19 dynamics is less than $10 \%$ for most of the days in case of Iran (except the first 32 days from the start of the pandemic, 31 of which have been deleted from Table 1 as non-informative).

We should additionally note that the second wave of pandemic seems to come to its end at the first decade of January 2021 in Iran (as in case of Germany). So, all the calculations for the combined first + second waves of pandemic should be interrupted in case of Iran within the pointed time period for the reason the third wave will come (with its specific features of evolving in time).

\section{Direct mathematical modelling of the COVID- 19's cases in USA}

Let us present non-classical trend of COVID-19's evolution in USA, where we should take into consideration the additional correcting coefficients for formulae of a type (1) or (2).

The aforementioned non-classical trend could be presented by the best-fitting formula (4) for the direct mathematical modelling of the burst of expansion of COVID-19 cases in USA:

$x_{n_{(\mathrm{USA})}}=\frac{200,000(1.38+0.15 \exp (0.0115(n+73)))}{0.1+300 \exp (-0.023(n+281))}$, 
Fig. 4 A schematic dynamics of coronavirus cases in Iran

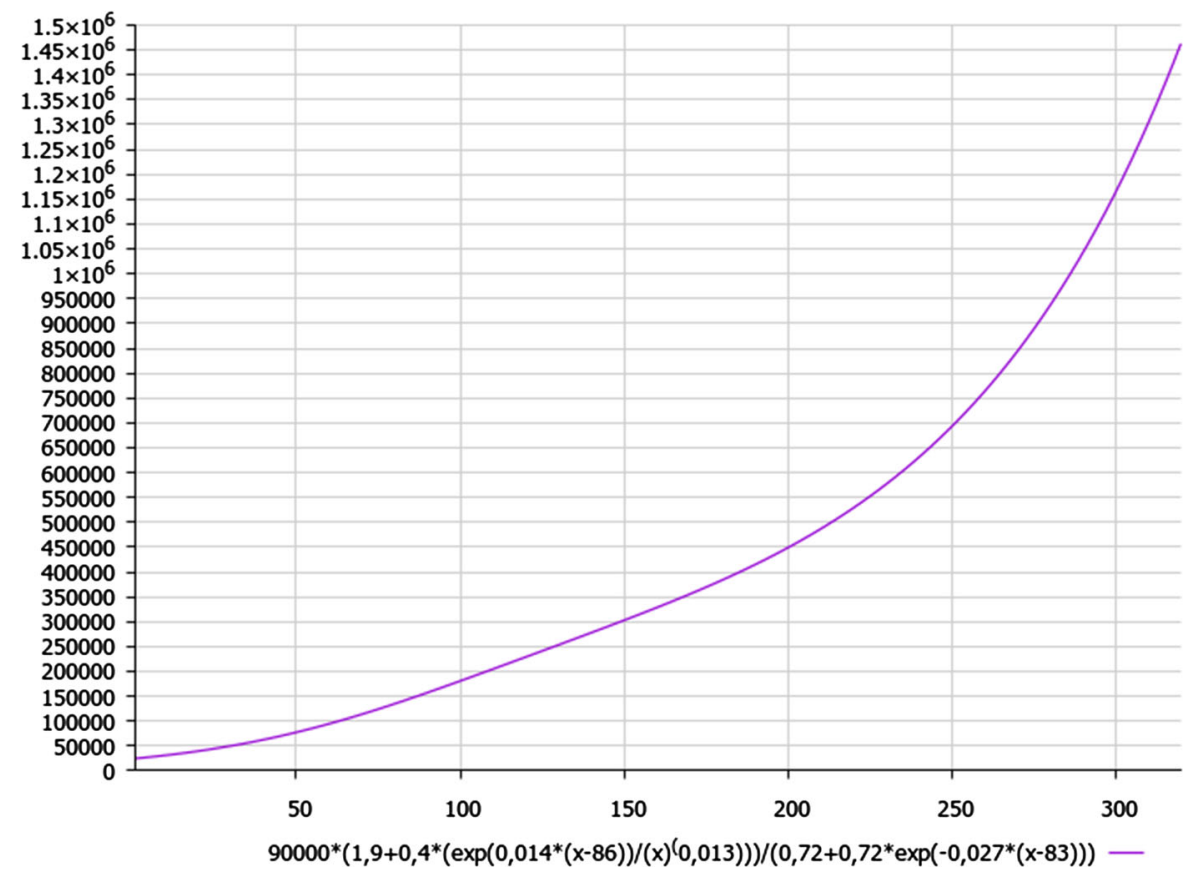

where $n$ is the current day, starting from 1 April 2020, which yields Fig. 5. (Let us note that the relative deviation between the calculated and real data of the COVID-19 dynamics is less than $10 \%$ for the data, presented in [2] for the case of USA, except first 20 days from the beginning of pandemic.)

Such large $10 \%$ deviation can be explained by accounting of those who may have been migrating into the USA during previous period of pandemic without strict accounting, across the board, e.g. from Brazil or via flight-communicating with other countries, including China, because USA did not restrict the flights at the beginning of pandemic sufficiently as it was reasonably required.

As we can see from Fig. 5, there is also no horizontal trend at the curve of pandemic. But, nevertheless, there is no bulge on a plot of the pandemic curve, determined by additional coefficient in the numerator of formula (4) [as e.g. in case of Iran, formula (3)].

We should especially note that modelling of the dynamics of COVID-19 pandemic in USA is not an easy matter because the statistic data for USA, reported in [2], are questionable (starting from 131 day of pandemic, official data have been changed several times a week: namely, data for all period of pandemic have been changed after 131, 138, 143, 150,
$152,154,155,159$ days of pandemic, etc.). Anyone can check this fact personally by online visiting [2] every day.

Such ambiguity at accounting the data of officially confirmed coronavirus cases could explain relatively large deviating in amount of $10 \%$ as stated above if we compare calculated vs. real data of the COVID-19 dynamics in the USA. (The aforementioned deviation in amount of $10 \%$ is much more than $8-9 \%$ in most cases of other countries.) The aforesaid manipulating of statistic data is a worst basis for the correct mathematical modelling of COVID-19' pandemic dynamics; no one country even Brazil (see the next section) does allow such a significant manipulation by COVID-19's official data of pandemic as it happened in the USA. It is worth noting that we cannot trust statistic data of COVID-19's pandemic in the USA (and Brazil) after 159 day of pandemic (6 September 2020). Nevertheless, we should note that the second wave of pandemic seems losing its power in USA with coming to its end at first decade of March 2021 (much more later than in cases of Germany or Iran). 
Table 1 Calculated versus real data for coronavirus cases in Iran

\begin{tabular}{|c|c|c|c|c|c|c|}
\hline Days & $\begin{array}{l}\text { Real data, } \\
\text { see [2] }\end{array}$ & $\begin{array}{l}\text { Key points } \\
\text { (calculated } \\
\text { data) }\end{array}$ & $\begin{array}{l}\text { Difference in } \% \% \\
\text { (calculated vs. real data) }\end{array}$ & $\begin{array}{l}\text { Difference current vs. } \\
\text { previous day (real data) }\end{array}$ & $\begin{array}{l}\text { Calculated } \\
\text { data }\end{array}$ & $\begin{array}{l}\text { Difference in } \% \% \\
\text { (calculated vs. real data) }\end{array}$ \\
\hline 32 & 47,593 & & & 2988 & 52,376 & 9 \\
\hline 33 & 50,468 & & & 2875 & 53,578 & 6 \\
\hline 34 & 53,183 & & & 2715 & 54,801 & 3 \\
\hline 35 & 55,743 & 56,047 & 0.5 & 2560 & 56,047 & 1 \\
\hline 36 & 58,226 & & & 2483 & 57,315 & -2 \\
\hline 37 & 60,500 & & & 2274 & 58,605 & -3 \\
\hline 38 & 62,589 & & & 2089 & 59,917 & -4 \\
\hline 39 & 64,586 & & & 1997 & 61,252 & -5 \\
\hline 40 & 66,220 & 62,610 & -5.8 & 1634 & 62,610 & -6 \\
\hline 41 & 68,192 & & & 1972 & 63,990 & -7 \\
\hline 42 & 70,029 & & & 1837 & 65,393 & -7 \\
\hline 43 & 71,686 & & & 1657 & 66,819 & -7 \\
\hline 44 & 73,303 & & & 1617 & 68,268 & -7 \\
\hline 45 & 74,877 & 69,739 & -7.4 & 1574 & 69,739 & -7 \\
\hline 46 & 76,389 & & & 1512 & 71,234 & -7 \\
\hline 47 & 77,995 & & & 1606 & 72,751 & -7 \\
\hline 48 & 79,494 & & & 1499 & 74,292 & -7 \\
\hline 49 & 80,868 & & & 1374 & 75,855 & -7 \\
\hline 50 & 82,211 & 77441 & -6.2 & 1343 & 77,441 & -6 \\
\hline 51 & 83,505 & & & 1294 & 79,050 & -6 \\
\hline 52 & 84,802 & & & 1297 & 80,681 & -5 \\
\hline 53 & 85,996 & & & 1194 & 82,335 & -4 \\
\hline 54 & 87,026 & & & 1030 & 84,011 & -4 \\
\hline 55 & 88,194 & 85,710 & -2.9 & 1168 & 85,710 & -3 \\
\hline 56 & 89,328 & & & 1134 & 87,431 & -2 \\
\hline 57 & 90,481 & & & 1153 & 89,175 & -1 \\
\hline 58 & 91,472 & & & 991 & 90,940 & -1 \\
\hline 59 & 92,584 & & & 1112 & 92,726 & 0 \\
\hline 60 & 93,657 & 94,535 & 0.9 & 1073 & 94,535 & 1 \\
\hline 61 & 94,640 & & & 983 & 96,364 & 2 \\
\hline 62 & 95,646 & & & 1006 & 98,215 & 3 \\
\hline 63 & 96,448 & & & 802 & 100,086 & 4 \\
\hline 64 & 97,424 & & & 976 & 101,978 & 4 \\
\hline 65 & 98,647 & 103,890 & 5.0 & 1223 & 103,890 & 5 \\
\hline 66 & 99,970 & & & 1323 & 105,823 & 6 \\
\hline 67 & 101,650 & & & 1680 & 107,775 & 6 \\
\hline 68 & 103,135 & & & 1485 & 109,746 & 6 \\
\hline 69 & 104,691 & & & 1556 & 111,736 & 6 \\
\hline 70 & 106,220 & 113,745 & 6.6 & 1529 & 113,745 & 7 \\
\hline 71 & 107,603 & & & 1383 & 115,772 & 7 \\
\hline 72 & 109,286 & & & 1683 & 117,817 & 7 \\
\hline 73 & 110,767 & & & 1481 & 119,880 & 8 \\
\hline 74 & 112,725 & & & 1958 & 121,960 & 8 \\
\hline
\end{tabular}


Table 1 continued

\begin{tabular}{|c|c|c|c|c|c|c|}
\hline Days & $\begin{array}{l}\text { Real data, } \\
\text { see [2] }\end{array}$ & $\begin{array}{l}\text { Key points } \\
\text { (calculated } \\
\text { data) }\end{array}$ & $\begin{array}{l}\text { Difference in } \% \% \\
\text { (calculated vs. real data) }\end{array}$ & $\begin{array}{l}\text { Difference current vs. } \\
\text { previous day (real data) }\end{array}$ & $\begin{array}{l}\text { Calculated } \\
\text { data }\end{array}$ & $\begin{array}{l}\text { Difference in } \% \% \\
\text { (calculated vs. real data) }\end{array}$ \\
\hline 75 & 114,533 & 124,057 & 7.7 & 1808 & 124,057 & 8 \\
\hline 76 & 116,635 & & & 2102 & 126,170 & 8 \\
\hline 77 & 118,392 & & & 1757 & 128,299 & 8 \\
\hline 78 & 120,198 & & & 1806 & 130,443 & 8 \\
\hline 79 & 122,492 & & & 2294 & 132,603 & 8 \\
\hline 80 & 124,603 & 134,777 & 7.5 & 2111 & 134,777 & 8 \\
\hline 81 & 126,949 & & & 2346 & 136,966 & 7 \\
\hline 82 & 129,341 & & & 2392 & 139,168 & 7 \\
\hline 83 & 131,652 & & & 2311 & 141,383 & 7 \\
\hline 84 & 133,521 & & & 1869 & 143,612 & 7 \\
\hline 85 & 135,701 & 145853 & 7.0 & 2180 & 145,853 & 7 \\
\hline 86 & 137,724 & & & 2023 & 148,105 & 7 \\
\hline 87 & 139,511 & & & 1787 & 150,369 & 7 \\
\hline 88 & 141,591 & & & 2080 & 152,644 & 7 \\
\hline 89 & 143,849 & & & 2258 & 154,930 & 7 \\
\hline 90 & 146,668 & 157,226 & 6.7 & 2819 & 157,226 & 7 \\
\hline 91 & 148,950 & & & 2282 & 159,531 & 7 \\
\hline 92 & 151,466 & & & 2516 & 161,846 & 6 \\
\hline 93 & 154,445 & & & 2979 & 164,169 & 6 \\
\hline 94 & 157,562 & & & 3117 & 166,501 & 5 \\
\hline 95 & 160,696 & 168,840 & $4.8 \%$ & 3134 & 168,840 & 5 \\
\hline 96 & 164,270 & & & 3574 & 171,187 & 4 \\
\hline 97 & 167,156 & & & 2886 & 173,541 & 4 \\
\hline 98 & 169,425 & & & 2269 & 175,902 & 4 \\
\hline 99 & 171,789 & & & 2364 & 178,269 & 4 \\
\hline 100 & 173,832 & 180642 & 3.8 & 2043 & 180,642 & 4 \\
\hline 101 & 175,927 & & & 2095 & 183,020 & 4 \\
\hline 102 & 177,938 & & & 2011 & 185,403 & 4 \\
\hline 103 & 180,156 & & & 2218 & 187,791 & 4 \\
\hline 104 & 182,525 & & & 2369 & 190,184 & 4 \\
\hline 105 & 184,955 & 192,580 & 4.0 & 2430 & 192,580 & 4 \\
\hline 106 & 187,427 & & & 2472 & 194,981 & 4 \\
\hline 107 & 189,876 & & & 2449 & 197,385 & 4 \\
\hline 108 & 192,439 & & & 2563 & 199,792 & 4 \\
\hline 109 & 195,051 & & & 2612 & 202,202 & 4 \\
\hline 110 & 197,647 & 204,615 & 3.4 & 2596 & 204,615 & 3 \\
\hline 111 & 200,262 & & & 2615 & 207,030 & 3 \\
\hline 112 & 202,584 & & & 2322 & 209,448 & 3 \\
\hline 113 & 204,952 & & & 2368 & 211,868 & 3 \\
\hline 114 & 207,525 & & & 2573 & 214,289 & 3 \\
\hline 115 & 209,970 & 216,713 & 3.1 & 2445 & 216,713 & 3 \\
\hline 116 & 212,501 & & & 2531 & 219,138 & 3 \\
\hline 117 & 215,096 & & & 2595 & 221,564 & 3 \\
\hline
\end{tabular}


Table 1 continued

\begin{tabular}{|c|c|c|c|c|c|c|}
\hline Days & $\begin{array}{l}\text { Real data, } \\
\text { see [2] }\end{array}$ & $\begin{array}{l}\text { Key points } \\
\text { (calculated } \\
\text { data) }\end{array}$ & $\begin{array}{l}\text { Difference in } \% \% \\
\text { (calculated vs. real data) }\end{array}$ & $\begin{array}{l}\text { Difference current vs. } \\
\text { previous day (real data) }\end{array}$ & $\begin{array}{l}\text { Calculated } \\
\text { data }\end{array}$ & $\begin{array}{l}\text { Difference in } \% \% \\
\text { (calculated vs. real data) }\end{array}$ \\
\hline 118 & 217,724 & & & 2628 & 223,992 & 3 \\
\hline 119 & 220,180 & & & 2456 & 226,421 & 3 \\
\hline 120 & 222,669 & 228,851 & 2.7 & 2489 & 228,851 & 3 \\
\hline 121 & 225,205 & & & 2536 & 231,282 & 3 \\
\hline 122 & 227,662 & & & 2457 & 233,715 & 3 \\
\hline 123 & 230,211 & & & 2549 & 236,149 & 3 \\
\hline 124 & 232,863 & & & 2652 & 238,583 & 2 \\
\hline 125 & 235,429 & 241,019 & 2.3 & 2566 & 241,019 & 2 \\
\hline 126 & 237,878 & & & 2449 & 243,456 & 2 \\
\hline 127 & 240,438 & & & 2560 & 245,894 & 2 \\
\hline 128 & 243,051 & & & 2613 & 248,333 & 2 \\
\hline 129 & 245,688 & & & 2637 & 250,774 & 2 \\
\hline 130 & 248,379 & 253,217 & 1.9 & 2691 & 253,217 & 2 \\
\hline 131 & 250,458 & & & 2079 & 255,660 & 2 \\
\hline 132 & 252,720 & & & 2262 & 258,106 & 2 \\
\hline 133 & 255,117 & & & 2397 & 260,554 & 2 \\
\hline 134 & 257,303 & & & 2186 & 263,003 & 2 \\
\hline 135 & 259,652 & 265,455 & 2.2 & 2349 & 265,455 & 2 \\
\hline 136 & 262,173 & & & 2521 & 267,909 & 2 \\
\hline 137 & 264,561 & & & 2388 & 270,366 & 2 \\
\hline 138 & 267,061 & & & 2500 & 272,826 & 2 \\
\hline 139 & 269,440 & & & 2379 & 275,289 & 2 \\
\hline 140 & 271,606 & 277,756 & 2.2 & 2166 & 277,756 & 2 \\
\hline 141 & 273,788 & & & 2182 & 280,226 & 2 \\
\hline 142 & 276,202 & & & 2414 & 282,701 & 2 \\
\hline 143 & 278,827 & & & 2625 & 285,179 & 2 \\
\hline 144 & 281,413 & & & 2586 & 287,663 & 2 \\
\hline 145 & 284,034 & 290,151 & 2.1 & 2621 & 290,151 & 2 \\
\hline 146 & 286,523 & & & 2489 & 292,645 & 2 \\
\hline 147 & 288,839 & & & 2316 & 295,144 & 2 \\
\hline 148 & 291,172 & & & 2333 & 297,650 & 2 \\
\hline 149 & 293,606 & & & 2434 & 300,162 & 2 \\
\hline 150 & 296,273 & 302,680 & 2.1 & 2667 & 302,680 & 2 \\
\hline 151 & 298,909 & & & 2636 & 305,206 & 2 \\
\hline 152 & 301,530 & & & 2621 & 307,740 & 2 \\
\hline 153 & 304,204 & & & 2674 & 310,282 & 2 \\
\hline 154 & 306,752 & & & 2548 & 312,832 & 2 \\
\hline 155 & 309,437 & 315,392 & 1.9 & 2685 & 315,392 & 2 \\
\hline 156 & 312,035 & & & 2598 & 317,960 & 2 \\
\hline 157 & 314,786 & & & 2751 & 320,539 & 2 \\
\hline 158 & 317,483 & & & 2697 & 323,128 & 2 \\
\hline 159 & 320,117 & & & 2634 & 325,728 & 2 \\
\hline 160 & 322,567 & 328,340 & 1.8 & 2450 & 328,340 & 2 \\
\hline
\end{tabular}


Table 1 continued

\begin{tabular}{|c|c|c|c|c|c|c|}
\hline Days & $\begin{array}{l}\text { Real data, } \\
\text { see [2] }\end{array}$ & $\begin{array}{l}\text { Key points } \\
\text { (calculated } \\
\text { data) }\end{array}$ & $\begin{array}{l}\text { Difference in } \% \% \\
\text { (calculated vs. real data) }\end{array}$ & $\begin{array}{l}\text { Difference current vs. } \\
\text { previous day (real data) }\end{array}$ & $\begin{array}{l}\text { Calculated } \\
\text { data }\end{array}$ & $\begin{array}{l}\text { Difference in } \% \% \\
\text { (calculated vs. real data) }\end{array}$ \\
\hline 161 & 324,692 & & & 2125 & 330,963 & 2 \\
\hline 162 & 326,712 & & & 2020 & 333,599 & 2 \\
\hline 163 & 328,844 & & & 2132 & 336,247 & 2 \\
\hline 164 & 331,189 & & & 2345 & 338,909 & 2 \\
\hline 165 & 333,699 & 341,585 & 2.3 & 2510 & 341,585 & 2 \\
\hline 166 & 336,324 & & & 2625 & 344,275 & 2 \\
\hline 167 & 338,825 & & & 2501 & 346,981 & 2 \\
\hline 168 & 341,070 & & & 2245 & 349,702 & 2 \\
\hline 169 & 343,203 & & & 2133 & 352,439 & 3 \\
\hline 170 & 345,450 & 355,193 & 2.7 & 2247 & 355,193 & 3 \\
\hline 171 & 347,835 & & & 2385 & 357,965 & 3 \\
\hline 172 & 350,279 & & & 2444 & 360,754 & 3 \\
\hline 173 & 352,558 & & & 2279 & 363,562 & 3 \\
\hline 174 & 354,764 & & & 2206 & 366,389 & 3 \\
\hline 175 & 356,792 & 369,235 & 3.4 & 2028 & 369,235 & 3 \\
\hline 176 & 358,905 & & & 2113 & 372,102 & 4 \\
\hline 177 & 361,150 & & & 2245 & 374,990 & 4 \\
\hline
\end{tabular}

Fig. 5 Schematic dynamics of coronavirus cases in USA

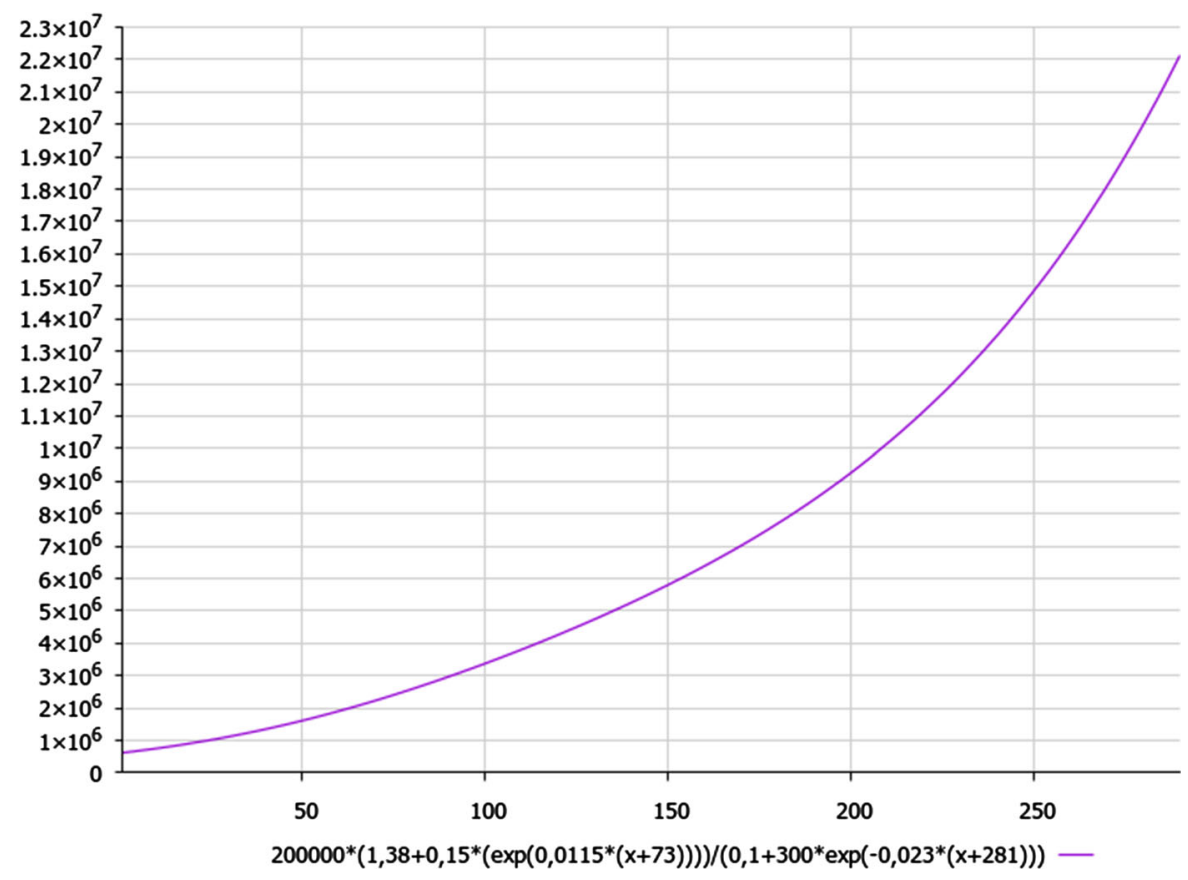




\section{Direct mathematical modelling of the COVID- 19's cases in Brazil}

Let us present non-classical trend of COVID-19's evolution in Brazil, where we should take into consideration the additional correcting coefficients for formulae of a type (1) or (2).

The aforementioned non-classical trend could be presented by the best-fitting formula (5) for the direct mathematical modelling of the coronavirus cases in Brazil:

$x_{n_{(\text {Brazil })}}=\frac{200,000(1.18+0.034 \exp (0.0094(n+220)))}{0.12+360 \exp (-0.05(n+68))}$,

where $n$ is the current day, starting from 1 April 2020, which yields Fig. 6. (It is worth noting that the relative deviation between the calculated and real data of the COVID-19 dynamics is less than $9 \%$ for most of the days in data, presented in [2] for the case of Brazil, except the first 42 days from the start of pandemic.)

Such deviation (9\%) can be considered as a good result, taking into consideration that most of the statistic data for Brazil are questionable due to a permanent interrupting in the process of reporting the amount of officially registered cases of illness (by political reasons). An interesting fact is that the level of epidemiological contamination by COVID-19 in Brazil is less for last day of previous and first day of current week during all the period of pandemic. This can be explained by weekend at offices which have been officially registering the cases of illness in Brazil.

As we can see from Fig. 6, there is also no horizontal trend on the curve of pandemic. Moreover, there is no any deviation (from general trend) or essential bulge on a plot at the beginning of pandemic, which is determined in case of, for example, Iran by additional coefficient $\sim 1 /\left(n^{\wedge}(0.013)\right)$ in the numerator of formula (3). Last but not least, let us note that the second wave of pandemic seems losing its power in Brazil with coming to its end at the middle of February 2021 (later than in cases of Germany or Iran).

\section{Direct mathematical modelling of the COVID- 19's cases in India}

Let us present non-classical trend of COVID-19's evolution in India, where we should take into consideration the additional correcting coefficients for formulae of a type (1) or (2). The aforementioned nonclassical trend could be presented by the best-fitting formula (6) for the direct mathematical modelling of the COVID-19 dynamics in India:
Fig. 6 Schematic dynamics of coronavirus cases in Brazil

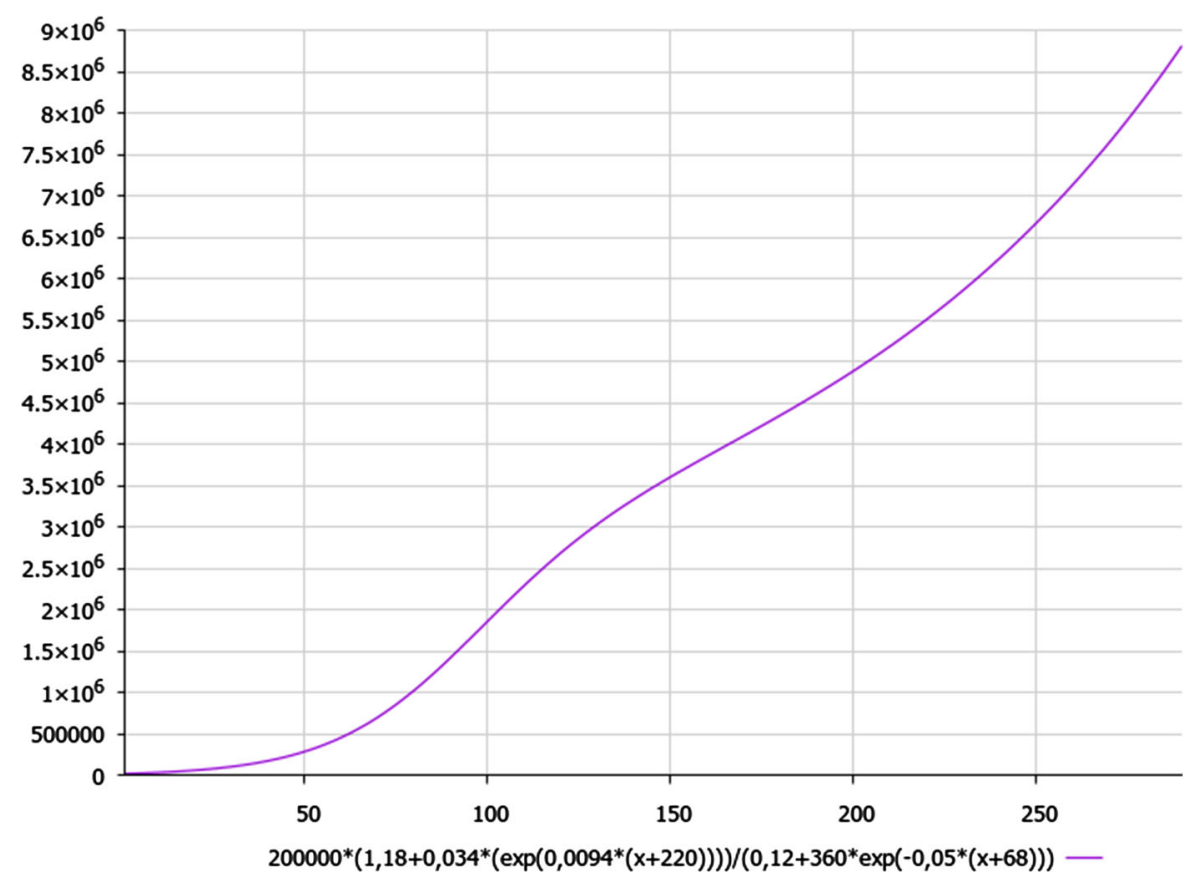


$x_{n_{\text {(India) }}}=\frac{100,000(6.73+7.9 \exp (0.004(n-110)))}{0.22+22 \exp (-0.04(n-33))}$,

where $n$ is the current day, starting from 1 April 2020, which yields Fig. 7

As we can see from Fig. 7, there is also no horizontal trend hereafter on the curve of pandemic.

As we can see from Table 2, the deviation of the calculated vs. real data of the COVID-19 dynamics is not more than $8 \%$ for most of the days in India, except the first 43 days from the start of the pandemic in India (40 of which have been deleted from Table 2 as noninformative).

Such an initial significant deviation can be explained by hidden migration from other surrounding countries directly into India without accounting of those people who have been infected outside the India at previous time period of pandemic (from China, Bangladesh, Pakistan, etc.).

Last but not least, it is worth to note that the second wave of pandemic seems to come to its end at the end of January 2021 in India (later than in cases of Germany and Iran). So, all calculations for the combined first + second waves of pandemic should be interrupted in case of India within this time period.

\section{Discussion}

First, we should mention that the governments of a lot of countries [1] are applying extraordinary efforts to overcome pandemic with the aim to protect the citizens of these countries. (So, they have demonstrated the classical general trends of a type of sigmoid curve at the end of first wave of COVID-19 pandemic.) But there are also obviously two types of non-classical general trends of COVID-19's evolving in the world:

- Tendency such as in Germany (2) (but, nevertheless, it means successful efforts of government) from the one hand and Russia (1) from the other hand (unsuccessful case), or e.g. USA (4), Brazil (5), India (6) (let us mention that this type of coronavirus pandemic is valid for all countries in Europe and most of the countries in world with various scenarios of the same type for general trends);

- Non-classical general trends (3) as in Iran's case, with the appropriate bulge on graphical plots (Fig. 4) at the beginning of first wave of pandemic.

As we can see from Figs. 4, 5, 6 and 7, there are no horizontal trends at the end of first wave of pandemic in USA, India, Brazil or Iran. Moreover, we should
Fig. 7 Schematic dynamics of coronavirus cases in India

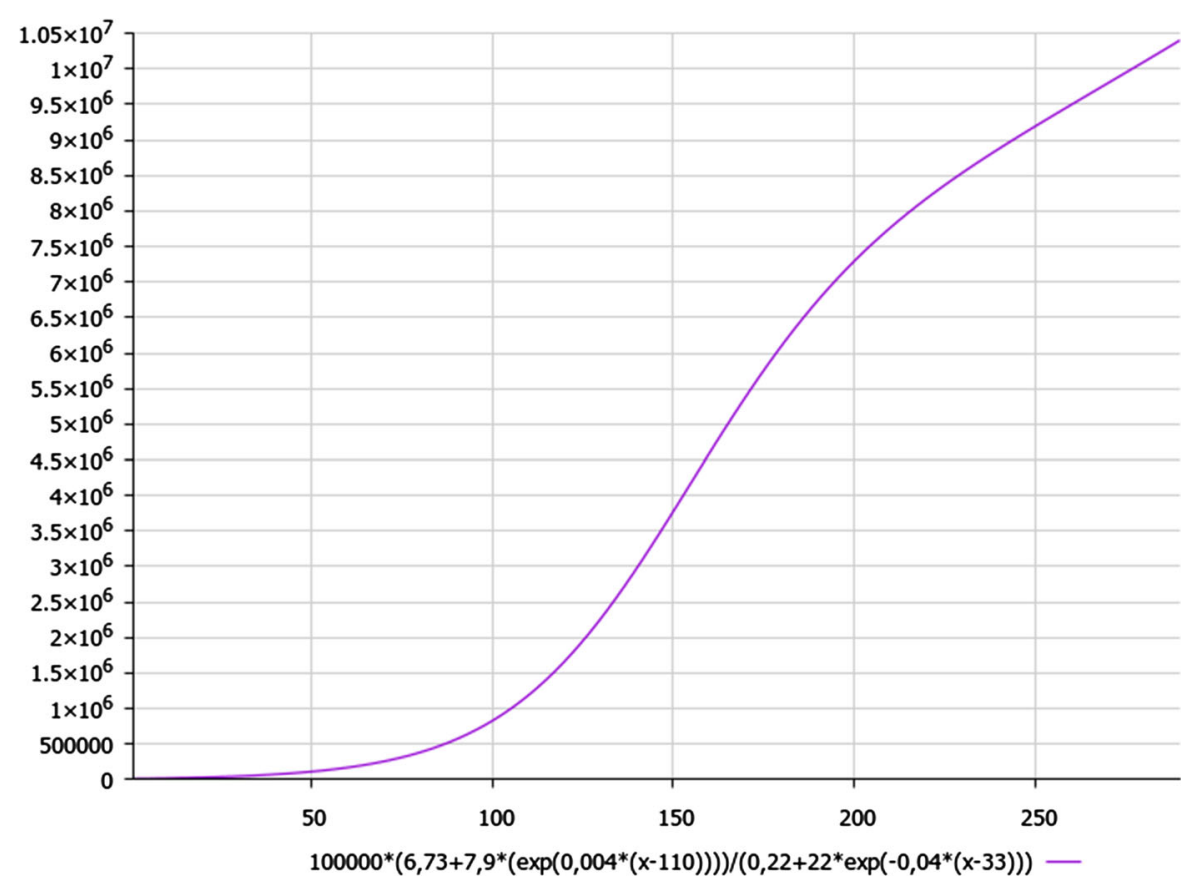


Table 2 Calculated versus real data for coronavirus cases in India

\begin{tabular}{|c|c|c|c|c|c|c|}
\hline Days & $\begin{array}{l}\text { Real data, } \\
\text { Ref. [2] }\end{array}$ & $\begin{array}{l}\text { Key points } \\
\text { (calculated } \\
\text { data) }\end{array}$ & $\begin{array}{l}\text { Difference in } \% \% \\
\text { (calculated vs. real data) }\end{array}$ & $\begin{array}{l}\text { Difference current vs. } \\
\text { previous day (real data) }\end{array}$ & $\begin{array}{l}\text { Calculated } \\
\text { data }\end{array}$ & $\begin{array}{l}\text { Difference in } \% \% \\
\text { (calculated vs. real } \\
\text { data) }\end{array}$ \\
\hline 41 & 70,768 & & & 3607 & 78,570 & 10 \\
\hline 42 & 74,292 & & & 3524 & 81,885 & 9 \\
\hline 43 & 78,055 & & & 3763 & 85,339 & 9 \\
\hline 44 & 81,997 & & & 3942 & 88,937 & 8 \\
\hline 45 & 85,784 & 92,685 & 7.4 & 3787 & 92,685 & 7 \\
\hline 46 & 90,648 & & & 4864 & 96,588 & 6 \\
\hline 47 & 95,698 & & & 5050 & 100,654 & 5 \\
\hline 48 & 100,328 & & & 4630 & 104,889 & 4 \\
\hline 49 & 106,475 & & & 6147 & 109,298 & 3 \\
\hline 50 & 112,028 & 113,891 & 1.6 & 5553 & 113,891 & 2 \\
\hline 51 & 118,226 & & & 6198 & 118,673 & 0 \\
\hline 52 & 124,794 & & & 6568 & 123,653 & -1 \\
\hline 53 & 131,423 & & & 6629 & 128,838 & -2 \\
\hline 54 & 138,536 & & & 7113 & 134,236 & -3 \\
\hline 55 & 144,950 & 139,856 & -3.6 & 6414 & 139,856 & -4 \\
\hline 56 & 150,793 & & & 5843 & 145,707 & -3 \\
\hline 57 & 158,086 & & & 7293 & 151,797 & -4 \\
\hline 58 & 165,386 & & & 7300 & 158,136 & -5 \\
\hline 59 & 173,491 & & & 8105 & 164,734 & -5 \\
\hline 60 & 181,827 & 171,601 & -6.0 & 8336 & 171,601 & -6 \\
\hline 61 & 190,609 & & & 8782 & 178,746 & -7 \\
\hline 62 & 198,370 & & & 7761 & 186,181 & -7 \\
\hline 63 & 207,191 & & & 8821 & 193,917 & -7 \\
\hline 64 & 216,824 & & & 9633 & 201,964 & -7 \\
\hline 65 & 226,713 & 210336 & -7.8 & 9889 & 210,336 & -8 \\
\hline 66 & 236,184 & & & 9471 & 219,044 & -8 \\
\hline 67 & 246,622 & & & 10,438 & 228,101 & -8 \\
\hline 68 & 257,486 & & & 10,864 & 237,520 & -8 \\
\hline 69 & 265,928 & & & 8442 & 247,313 & -8 \\
\hline 70 & 274,780 & 257495 & -6.7 & 8852 & 257,495 & -7 \\
\hline 71 & 287,155 & & & 12,375 & 268,081 & -7 \\
\hline 72 & 298,283 & & & 11,128 & 279,084 & -7 \\
\hline 73 & 309,603 & & & 11,320 & 290,519 & -7 \\
\hline 74 & 321,626 & & & 12,023 & 30,403 & -6 \\
\hline 75 & 332,783 & 314,750 & -5.7 & 11,157 & 314,750 & -6 \\
\hline 76 & 343,026 & & & 10,243 & 327,578 & -5 \\
\hline 77 & 354,161 & & & 11,135 & 340,902 & -4 \\
\hline 78 & 367,264 & & & 13,103 & 354,741 & -4 \\
\hline 79 & 381,091 & & & 13,827 & 369,110 & -3 \\
\hline 80 & 395,812 & 384,030 & -3.1 & 14,721 & 384,030 & -3 \\
\hline 81 & 411,727 & & & 15,915 & 399,516 & -3 \\
\hline 82 & 426,910 & & & 15,183 & 415,590 & -3 \\
\hline 83 & 440,450 & & & 13,540 & 432,269 & -2 \\
\hline
\end{tabular}


Table 2 continued

\begin{tabular}{|c|c|c|c|c|c|c|}
\hline Days & $\begin{array}{l}\text { Real data, } \\
\text { Ref. [2] }\end{array}$ & $\begin{array}{l}\text { Key points } \\
\text { (calculated } \\
\text { data) }\end{array}$ & $\begin{array}{l}\text { Difference in } \% \% \\
\text { (calculated vs. real data) }\end{array}$ & $\begin{array}{l}\text { Difference current vs. } \\
\text { previous day (real data) }\end{array}$ & $\begin{array}{l}\text { Calculated } \\
\text { data }\end{array}$ & $\begin{array}{l}\text { Difference in } \% \% \\
\text { (calculated vs. real } \\
\text { data) }\end{array}$ \\
\hline 84 & 456,115 & & & 15,665 & 449,573 & -1 \\
\hline 85 & 472,985 & 467,522 & -1.2 & 16,870 & 467,522 & -1 \\
\hline 86 & 491,170 & & & 18,185 & 486,136 & -1 \\
\hline 87 & 509,446 & & & 18,276 & 505,436 & -1 \\
\hline 88 & 529,577 & & & 20,131 & 525,442 & -1 \\
\hline 89 & 549,197 & & & 19,620 & 546,176 & -1 \\
\hline 90 & 567,536 & 567,659 & 0.0 & 18,339 & 567,659 & 0 \\
\hline 91 & 585,792 & & & 18,256 & 589,913 & 1 \\
\hline 92 & 605,220 & & & 19,428 & 612,960 & 1 \\
\hline 93 & 627,168 & & & 21,948 & 636,821 & 2 \\
\hline 94 & 649,889 & & & 22,721 & 661,520 & 2 \\
\hline 95 & 673,904 & 687,077 & 1.9 & 24,015 & 687,077 & 2 \\
\hline 96 & 697,836 & & & 23,932 & 713,516 & 2 \\
\hline 97 & 720,346 & & & 22,510 & 740,858 & 3 \\
\hline 98 & 743,481 & & & 23,135 & 769,127 & 3 \\
\hline 99 & 769,052 & & & 25,571 & 798,344 & 4 \\
\hline 100 & 794,842 & 828,531 & 4.1 & 25,790 & 828,531 & 4 \\
\hline 101 & 822,603 & & & 27,761 & 859,710 & 4 \\
\hline 102 & 850,358 & & & 27,755 & 891,902 & 5 \\
\hline 103 & 879,466 & & & 29,108 & 925,130 & 5 \\
\hline 104 & 907,645 & & & 28,179 & 959,413 & 5 \\
\hline 105 & 937,487 & 994,771 & 5.8 & 29,842 & 994,771 & 6 \\
\hline 106 & 970,169 & & & 32,682 & $1,031,225$ & 6 \\
\hline 107 & $1,005,637$ & & & 35,468 & $1,068,794$ & 6 \\
\hline 108 & $1,040,457$ & & & 34,820 & $1,107,495$ & 6 \\
\hline 109 & $1,077,864$ & & & 37,407 & $1,147,346$ & 6 \\
\hline 110 & $1,118,107$ & $1,188,365$ & 5.9 & 40,243 & $1,188,365$ & 6 \\
\hline 111 & $1,154,917$ & & & 36,810 & $1,230,565$ & 6 \\
\hline 112 & $1,194,085$ & & & 39,168 & $1,273,962$ & 6 \\
\hline 113 & $1,239,684$ & & & 45,599 & $1,318,570$ & 6 \\
\hline 114 & $1,288,130$ & & & 48,446 & $1,364,399$ & 6 \\
\hline 115 & $1,337,022$ & $1,411,461$ & 5.3 & 48,892 & $1,411,461$ & 5 \\
\hline 116 & $1,385,494$ & & & 48,472 & $1,459,764$ & 5 \\
\hline 117 & $1,436,019$ & & & 50,525 & $1,509,316$ & 5 \\
\hline 118 & $1,482,503$ & & & 46,484 & $1,560,124$ & 5 \\
\hline 119 & $1,532,135$ & & & 49,632 & $1,612,190$ & 5 \\
\hline 120 & $1,584,384$ & $1,665,518$ & 4.9 & 52,249 & $1,665,518$ & 5 \\
\hline 121 & $1,639,350$ & & & 54,966 & $1,720,107$ & 5 \\
\hline 122 & $1,697,054$ & & & 57,704 & $1,775,956$ & 4 \\
\hline 123 & $1,751,919$ & & & 54,865 & $1,833,061$ & 4 \\
\hline 124 & $1,804,702$ & & & 52,783 & $1,891,416$ & 5 \\
\hline 125 & $1,855,331$ & $1,951,013$ & 4.9 & 50,629 & $1,951,013$ & 5 \\
\hline 126 & $1,906,613$ & & & 51,282 & $2,011,842$ & 5 \\
\hline
\end{tabular}


Table 2 continued

\begin{tabular}{|c|c|c|c|c|c|c|}
\hline Days & $\begin{array}{l}\text { Real data, } \\
\text { Ref. [2] }\end{array}$ & $\begin{array}{l}\text { Key points } \\
\text { (calculated } \\
\text { data) }\end{array}$ & $\begin{array}{l}\text { Difference in } \% \% \\
\text { (calculated vs. real data) }\end{array}$ & $\begin{array}{l}\text { Difference current vs. } \\
\text { previous day (real data) }\end{array}$ & $\begin{array}{l}\text { Calculated } \\
\text { data }\end{array}$ & $\begin{array}{l}\text { Difference in } \% \% \\
\text { (calculated vs. real } \\
\text { data) }\end{array}$ \\
\hline 127 & $1,963,239$ & & & 56,626 & $2,073,888$ & 5 \\
\hline 128 & $2,025,409$ & & & 62,170 & $2,137,138$ & 5 \\
\hline 129 & $2,086,864$ & & & 61,455 & $2,201,573$ & 5 \\
\hline 130 & $2,152,020$ & $2,267,174$ & 5.1 & 65,156 & $2,267,174$ & 5 \\
\hline 131 & $2,214,137$ & & & 62,117 & $2,333,918$ & 5 \\
\hline 132 & $2,267,153$ & & & 53,016 & $2,401,780$ & 6 \\
\hline 133 & $2,328,405$ & & & 61,252 & $2,470,733$ & 6 \\
\hline 134 & $2,395,471$ & & & 67,066 & $2,540,746$ & 6 \\
\hline 135 & $2,459,613$ & $2,611,788$ & 5.8 & 64,142 & $2,611,788$ & 6 \\
\hline 136 & $2,525,222$ & & & 65,609 & $2,683,824$ & 6 \\
\hline 137 & $2,589,208$ & & & 63,986 & $2,756,817$ & 6 \\
\hline 138 & $2,647,316$ & & & 58,108 & $2,830,728$ & 6 \\
\hline 139 & $2,701,604$ & & & 54,288 & $2,905,517$ & 7 \\
\hline 140 & $2,766,626$ & $2,981,139$ & 7.2 & 65,022 & $2,981,139$ & 7 \\
\hline 141 & $2,835,822$ & & & 69,196 & $3,057,550$ & 7 \\
\hline 142 & $2,904,329$ & & & 68,507 & $3,134,704$ & 7 \\
\hline 143 & $2,973,368$ & & & 69,039 & $3,212,550$ & 7 \\
\hline 144 & $3,043,436$ & & & 70,068 & $3,291,040$ & 8 \\
\hline 145 & $3,105,185$ & $3,370,122$ & 7.9 & 61,749 & $3,370,122$ & 8 \\
\hline 146 & $3,164,881$ & & & 59,696 & $3,449,742$ & 8 \\
\hline
\end{tabular}

note that there is the appropriate bulge on the graphical plot of first + second wave of pandemic in Iran, which is determined by additional coefficient $\sim 1$ / $\left(n^{\wedge}(0.013)\right)$ in the numerator of formula (3).

We expect that the second wave of pandemic will pass its peak at the end of December 2020 for various countries, so all the approximated formulae for COVID-19's evolution in human society should be corrected afterwards, according to the updated dynamics for the confirmed cases of illness in these countries. Videlicet, the second wave of pandemic will come to the end at the first decade of January 2021 in Germany and Iran (but at the end of January 2021 in India as well), so we should restrict ourselves in modelling first and second waves of pandemic within this period of time for these countries.

Let us note that the same conclusion (as in case of Iran) can be made for most of the countries from Middle East such as Iraq (we can see a little bulge at the beginning of the graphical plot of coronavirus cases in this country [2]), Azerbaijan (a little bulge), Saudi Arabia (a little bulge at the end of first wave of pandemic), Uzbekistan (bulge of middle size), Kazakhstan (a little bulge, but nevertheless), Lebanon (a huge bulge at the beginning of pandemic), Jordan (the same huge bulge as in case of Lebanon), State of Palestine (a huge bulge at the middle of pandemic), Libya (bulge of a little size but during a long time period), Syria (a middle-sized bulge at the beginning of pandemic) and, unexpectedly, such countries as Djibouti (bulge of middle size), Niger (a more huge bulge than in other countries), Ghana (oscillating curve of bulge of middle size close to the middle of first wave of pandemic), Rwanda (a middle-sized bulge at the end of first wave of pandemic), Costa Rica (a big-sized bulge), Madagascar (bulge of middle size but during a long time period), Malta (combination of two bulges: a middle-sized bulge at the beginning 
along with the second huge bulge at the end of first wave of pandemic), Singapore (a middle-sized bulge), North Macedonia (bulge of middle size but during a long time period), Sri Lanka (a middle-sized bulge close to the end of the first wave of pandemic), Paraguay (a middle-sized bulge at the end of first wave of pandemic), Jamaica (a huge bulge at the middle of pandemic), Myanmar (a huge bulge during a long time period at the end of pandemic), Cayman Islands (bulge of middle size) and also a negligible bulge we can see on curve of coronavirus cases in Denmark.

As for the possible deviations in the data of registered cases of COVID-19 [2] in various countries (due to reporting bias, censoring due to lack of testing availability and asymptomatic infection), we based our research on the data which have been crosschecked and verified from various sources, including data from COVID-19 Dashboard by the Center for Systems Science and Engineering (CSSE) at Johns Hopkins University (JHU) [13]. We should especially note that correct modelling of the dynamics of COVID-19 pandemic in USA is impossible because the statistic data for USA are questionable (starting from 131st day of pandemic, where 1st day of pandemic is 1 April 2020, official data have been changed several times a week).

Last but not least, let us note that the welldeveloped epidemic spread over spatially extended regions (such as the USA and Russia) cannot be considered within a local model with the complete mixing that leads to the logistic cumulative curve. So, we have considered here the model of first approximation which allows to understand the mean-time trends of COVID-19 evolution for the first + second waves of pandemic for USA, Brazil and Russia, or predict the approximated time period of the upcoming third wave of pandemic in cases of India, Germany and Iran.

Ending discussion, one more (but important) remark should be added regarding the reason why the obtained results are achieved in the process of selfdeveloping of coronavirus pandemic in all the world. Namely, why this had happened or is there any reasonable (physical) reason why the current pandemic has not lost his death power up during a year after its beginning in January of 2020 in China? Indeed, most of the previous pandemics have been exhausting their power with further tending to the classical general trend or the simple sigmoid curve like in case of China (Fig. 1).

But in case of COVID-19 pandemic, we conclude that the same type of coronavirus pandemic is valid for most of the countries in world with similar scenarios of the same type for general trends presented by the curve of modified sigmoid type with up-inclination of the upper limit of saturation (at the end of first wave of pandemic). There are no horizontal trends at the curves of pandemic in most countries in the world. (The horizontal trend could be associated with the exhausting of pandemic power in this or that country.)

Our assumption in this regard that "charging potential" of COVID-19 is in a manner more related to the host than virus [1] makes the aforementioned a catastrophic acceleration scenario to be realistic insofar as possible. In other words, virus (spreading successfully inside the human society) gains its energy for self-developing from humankind directly as collective vampire. The only way to overcome the pandemic in future is, obviously, the total vaccination [9] of all the humankind or the total local quarantine (by the same way as China government launched at the beginning in January of 2020 in China's Hubei Province), in addition to social distancing (and wearing a masks), of course. These are the rules of the COVID-19, which have been dictated to humankind by novel coronavirus.

\section{Conclusion}

We have presented in the current analytic research the results of direct mathematical modelling of the nonclassical trends of COVID-19's evolution in world which can be divided into two types: European countries (such as Germany or from the other hand, unexpectedly, India) versus Middle East countries (the most typical represented by Iran).

Basing on the presented results, we can estimate mean-time perspectives of evolution of COVID-19 pandemic in various countries. For example, if we proceed the general trend of a type (1), (2) for the modified sigmoid curve (or logistic curve) which stems from our model [1], we will obtain that scenario of pandemic in Russia is worse than in Germany, alas! (Fig. 8). Nevertheless, we should note that the second wave of pandemic seems losing its power in Russia with its ending at last decade of February 2021 (later 
Fig. 8 A schematic prognosis for the dynamics of total coronavirus cases in Russia during 1 year. The start is 1 April 2020

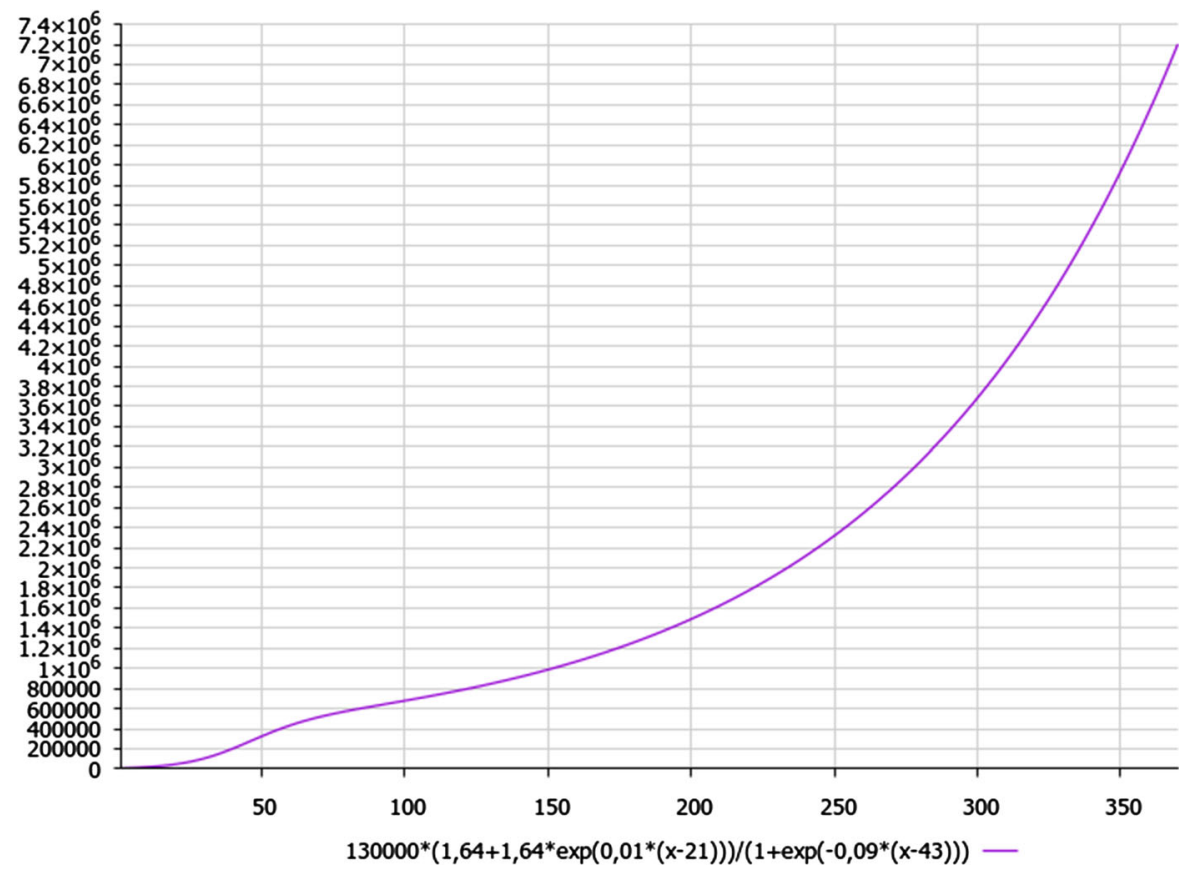

pandemic rate). It means that we should suggest revolving scheme for calculating algorithm with respect to the cascade of waves of pandemic: at each calculation step, the final solution values of the previous stage of pandemic should be considered to be the initial conditions for the next calculation step (next wave of pandemic). In [1], we have suggested approximated formulae for the first wave of pandemic in case of Russia and Germany; in the current research, we decode the second wave of pandemic for the key six countries (including USA, India, Brazil, Russia, Iran and Germany).

Thus, in this article we suggest approach how to estimate the evolution of COVID-19 pandemic in time for the restricted chosen period of time associated with the second wave of pandemic. This is definitely new insight for presenting clear mathematical algorithm of modelling pandemic in a form which allows us to gain new useful information about mean-time and also long-term COVID-19 evolution with respect to critical level of the aforementioned epidemiological contamination in human society. Meanwhile, it obviously means that suggested method should enrich our knowledge about evolution of COVID-19 from mathematical point of view. Indeed, such a novel approach differs from most of the existing theories for describing the evolution of the viruses in human society 
(which are based mainly on modelling such a dynamics with the help of appropriate systems of ODEs or by the stochastic methods).

According to our understanding, the suggested approach is the significant theoretical tool (with practical application of mathematical algorithms) for the analysis of the global evolution of various pandemics and it can be used in future researches for determining the extent of the biological hazard that poses a threat to the health of living organisms, primarily humans, at the chosen step of evolving pandemic.

Also, remarkable articles [14-20] should be cited, which concern the problem under consideration.

\section{Remarks (with highlights)}

- Analytic modelling of humankind amount infected by COVID-19 has been developed.

- Finite chains of recurrent sequences describe how population evolve over time.

- Semi-analytical ansatz is suggested for such a recurrent solving procedure.

- The proper formulae for COVID-19 evolving inside human population are obtained.

- Formulae for non-classical trends of pandemic are presented for six countries.

- Modified sigmoid curves with up-inclination at the end of first wave are obtained.

- Plots for such formulae can be divided into two types: with bulge or no at beginning.

- Second wave of pandemic will pass its peak at the end of December 2020 for six countries.

- Second wave will come to end at the first decade of January in 2021 for Germany and Iran.

- Second wave will come to end at the end of January 2021 in India, $3^{\text {rd }}$ wave will be born.

- Trends of pandemic for USA, India, Brazil, Russia, Iran and Germany are presented.

Let us explain or clarify how each of the parameters influences the performance of the proposed approach. Denominators in formulae (1), (2), (3), (4), (5) and (6) yield the trends of classical sigmoid curves (Fig. 1), whereas numerators yield the modified sigmoid curves with up-inclination at the end of first wave of pandemic (Figs. 2, 3, 4, 5, 6, 7, 8). In addition, if in the numerator of formula there is an polynomial extent of the current day of pandemic (e.g., in formula (3) for Iran) it should mean the presence of the appropriate bulge (Fig. 4 at zoom) at the beginning of the graphical plot of coronavirus curve as in case of Iran (or other Middle East countries).

There is only one variable parameter for each formulae, namely the number of days from the start of the pandemic (in this or that countries). Also, geometry of the modified sigmoid curves strongly depends on the initial data (the amount of infected people officially registered at the 1 st day of pandemic).

Acknowledgements The authors are thankful to unknown esteemed reviewers with respect to their valuable efforts and advices which have improved structure of the article significantly (namely, to add section "Remarks (with highlights)" with some discussions about insight of the main results). Authors appreciate advices of Dr. Victor Christianto (Indonesia), who is a native speaker, regarding the quality of English language in this work.

Author contributions In this research, SE is responsible for the results of the article, the obtaining of exact solutions, simple algebra manipulations, calculations, the representation of a general ansatz and calculations of graphical solutions, approximation and also is responsible for the search of approximate solutions. AR was responsible for approximated solving of the algebraic Eqs. (6) and (7) in [1] by means of advanced numerical methods as well as, videlicet, is responsible for applying numerical data of calculations to the current research.

Funding Not applicable.

Availability of data and materials The data for this paper are available by contacting the corresponding author.

Code availability To obtain graphical results, online software package was used: http://grafikus.ru/.

\section{Compliance with ethical standards}

Conflict of interest The authors declare that there is no conflict of interests regarding publication of article.

\section{References}

1. Ershkov, S.V., Christianto, V., Rachinskaya, A.L., Prosviryakov, E.Yu.: A nonlinear heuristic model for estimation of Covid-19 impact to world population. Rom. Rep. Phys. 72(3), 1-15 (2020)

2. https://www.worldometers.info/coronavirus/.

3. Persaud-Sharma, D., O'Leary, J.P.: Fibonacci series, golden proportions, and the human biology. Austin J. Surg. 2(5), 106 (2015) 
4. Podani, J., Kun, Á., Szilágyi, A.: How fast does Darwin's elephant population grow? J. Hist. Biol. 51, 259-281 (2018)

5. Bjørnstad, O.N., Shea, K., Krzywinski, M., Altman, N.: Modeling infectious epidemics. Nat. Methods 17, 455-456 (2020)

6. Anderson, R.M., Anderson, B., May, R.M.: Infectious Diseases of Humans: Dynamics and Control. Oxford University Press, Oxford (1992)

7. Bjørnstad, O.N.: Epidemics: Models and Data Using R. Springer, Berlin (2018)

8. Weiss, H.: The SIR model and the foundations of public health. Mater. Matemàtics 2013(3), 17 (2013)

9. Anderson, R.M., May, R.M.: Vaccination and herd immunity to infectious diseases. Nature 318, 323-329 (1985)

10. Verhulst, P.-F.: Recherches mathematiques sur la loi d'accroissement de la population. Nouv. mem. de l'Academie Royale des Sci. et Belles-Lettres de Bruxelles 18, 1-41 (1845)

11. Verhulst, P.-F.: Deuxieme memoire sur la loi d'accroissement de la population. Mem. de l'Academie Royale des Sci., des Lettres et des Beaux-Arts de Belgique 20, 1-32 (1847)

12. Altan, A., Karasu, S.: Recognition of COVID-19 disease from X-ray images by hybrid model consisting of 2D curvelet transform, chaotic salp swarm algorithm and deep learning technique. Chaos Solitons Fractals 140, 110071 (2020)
13. https://coronavirus.jhu.edu/map.html

14. Arnold, V.I.: Catastrophe Theory, 3rd edn. Springer-Verlag, Berlin (1992)

15. Wu, J.T., Leung, K., Leung, G.M.: Nowcasting and forecasting the potential domestic and international spread of the 2019-nCoV outbreak originating in Wuhan, China: a modelling study. Lancet 395(10225), 689-697 (2020)

16. Faranda, D., Alberti, T.: Modelling the second wave of COVID-19 infections in France and Italy via a Stochastic SEIR model. Chaos Interdiscip. J. Nonlinear Sci. 30, 111101 (2020). https://doi.org/10.1063/5.0015943

17. Iqbal, Z., Rehman, M.A.U., Baleanu, D., Ahmed, N., Raza, A., Rafiq, M.: Mathematical and numerical investigations of the fractional order epidemic model with constant vaccination strategy. Rom. Rep. Phys. 73(3), 1-19 (2020)

18. Arqub, O.A., Abo-Hammour, Z.: Numerical solution of systems of second-order boundary value problems using continuous genetic algorithm. Inf. Sci. 279, 396-415 (2014)

19. Arqub, O.A., Odibat, Z., Al-Smadi, M.: Numerical solutions of time-fractional partial integrodifferential equations of Robin functions types in Hilbert space with error bounds and error estimates. Nonlinear Dyn. 94, 1819-1834 (2018)

20. Arqub, O.A., Al-Smadi, M.: Numerical solutions of Riesz fractional diffusion and advection-dispersion equations in porous media using iterative reproducing kernel algorithm. J. Porous Media 23(8), 783-804 (2020) 